\title{
The Study of Higher Origin of Facial Artery and its Surgical Significance
}

\author{
Ashutosh Mangalgiri • Laxmi Narayan Namdev • \\ Devendra Mahore $\cdot$ Madan Kapre
}

Received: 11 October 2014 / Accepted: 15 October 2014/Published online: 21 October 2014

(C) Association of Otolaryngologists of India 2014

\begin{abstract}
Facial artery plays a key role in blood supply of the face. Facial artery one of the anterior branches of the external carotid artery originates within the carotid triangle. Variation in the origin of the facial artery was observed on two sides out of 60 sides in 30 cadavers. Facial artery was observed originating at the level just below the maxillary artery within the parotid gland. Facial artery may originate as linguo-facial trunk or thyro-linguo-facial trunk. Other developmental variations have also been described in the literature like, agenesis of facial artery, enlarged facial artery, hypoplastic facial artery. Variability in situation may complicate the surgery. Therefore maxillofacial surgeon, plastic surgeons and head \& neck surgeon should be aware of such variation.
\end{abstract}

Keywords Facial artery - Higher division .

Branches of external carotid artery - Arterial variations . Variations

A. Mangalgiri $(\bowtie)$

Chirayu Medical College \& Hospital, Bhopal 462030, India

e-mail: ashutoshmangalgiri@yahoo.co.in

L. N. Namdev

Bhopal, India

e-mail: Innamdev@rediffmail.com

D. Mahore

Government Medical College, Miraj, India

e-mail: mahoredm@gmail.com

M. Kapre

Neeti Clinics, Nagpur, India

e-mail: madankapre@gmail.com

\section{Introduction}

Knowledge of anatomy is a cornerstone for surgery. Face is richly supplied by facial artery and transverse facial artery. Rich vascularity of face permits the reconstruction of various flaps for closure of defects.

Facial artery arises as anterior branch of the external carotid artery within the carotid triangle. In its cervical course it runs upward and lying deep to the posterior belly of diagastric and stylohyoid. Running upwards grooving between the medial surface of mandible and lateral surface of submandibular gland, it then hooks the lower border of mandible at the anteroinferior corner of masseter muscle and ascends on face. Facial artery may arise singly or in common with lingual artery. Many developmental variations have been described in the literature like, agenesis of facial artery [1], enlarged facial artery, hypoplastic facial artery [2]. In present study, higher origin of facial artery was observed and its surgical importance and relations were discussed.

\section{Materials and Methods}

The study was conducted in the department of Anatomy, Chirayu Medical College \& Hospital Bhopal. Thirty cadavers were dissected for the study. Origin of the facial artery was observed on 60 sides of the 30 cadavers dissected. Facial artery was traced to its origin from external carotid artery. Parotid gland was also removed by piecemeal dissection to trace the origin of facial artery.

\section{Observations}

External carotid artery was exposed and origin of the facial artery was traced. In two cadavers higher origin of facial 


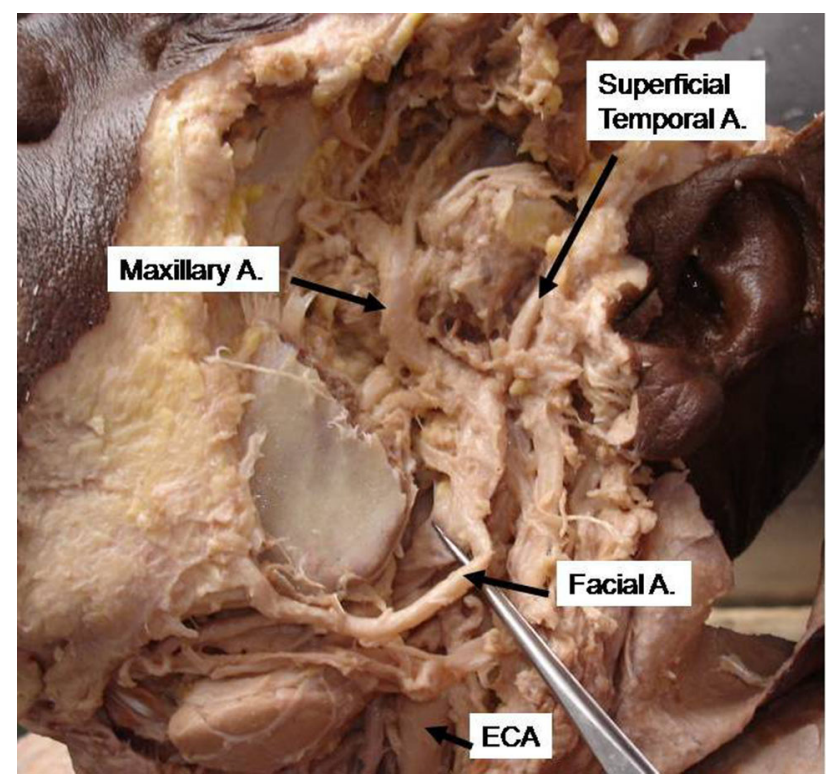

Fig. 1 Illustration showing higher origin of facial artery. ECA external carotid artery

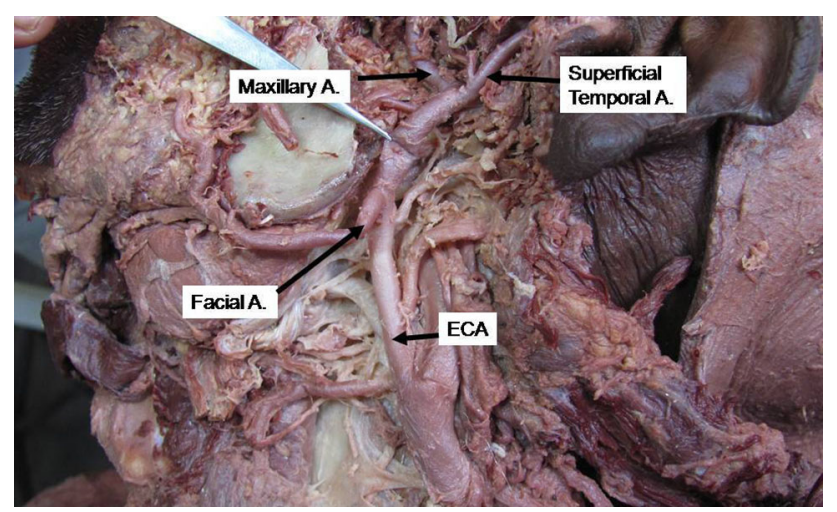

Fig. 2 Illustration showing higher origin of facial artery. ECA external carotid artery

artery was observed on left side $(3.33 \%)$. Facial artery was found originating from the external carotid artery just below the origin of maxillary artery within the parotid gland. Facial artery was descending along the posterior border of the mandible. On further tracing, artery turns forwards and medially along the lower border of the mandible. It hooks the lower border of the mandible and turns upwards at the antero-inferior angle of the masseter (Figs. 1, 2).

Facial artery on left side was related anteriorly to the posterior border of the ramus of mandible and posteriorly to the sternocleidomastoid. Superficially covered by the cervicofacial trunk of facial nerve and its branches buccal, marginal mandibular and cervical (Fig. 3). It was also related to the retromandibular vein superficially.

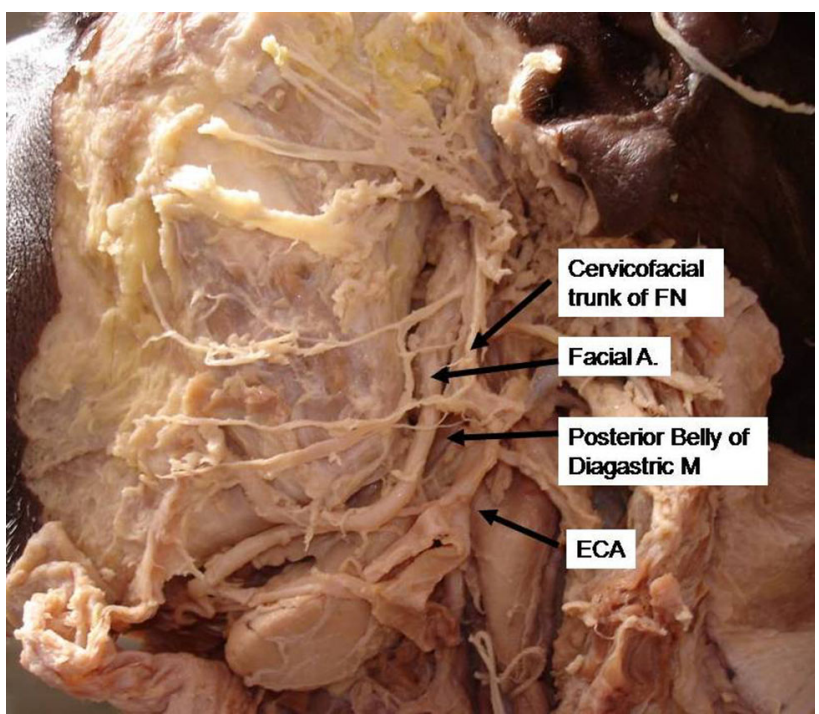

Fig. 3 Illustration showing relations of facial artery. ECA external carotid artery, $F N$ facial nerve

\section{Discussion}

Facial artery variants are not uncommon. It may arise in the form a single stem as linguo-facial trunk $[3,4]$ or thyrolinguofacial trunk [5]. In absence of external carotid artery, facial artery may arise from internal carotid artery [3] or from the common carotid artery [6]. On rare occasion facial artery may remain absent, the other branches may then takeover the blood supply of face [1]. Higher origin of facial artery may be mis-diagnosed as absence of facial artery.

In two cases facial artery on left side was branching off higher up from the external carotid artery within the parotid gland (intraparotid). Very few cases have been reported in literature about the higher origin of facial artery within the parotid gland (intraparotid) [7] and also within the diagastric triangle [8]. In situation of higher origin of facial artery it is liable to damage during parotid surgeries. Control of bleeding may be difficult due to presence of terminal branches of facial nerve in close vicinity. In present situation facial artery may be mistaken for the external carotid artery and could be ligated instead of external carotid artery. Knowledge of facial artery is also important in raising the mayo-cutaneous flaps [9] and also to the plastic surgeons in mapping for facial reconstructive operations [10].

Facial artery may get damaged during radiation or by an iatrogenic injury during surgery. Pseudo-aneurysm of external carotid artery branch develops, following radiotherapy for nasopharyngeal carcinoma [11]. There may be rupture of irradiated arteries in cases with head and neck cancers. In case of pseudo-aneurysm of a branch from external carotid artery, management of hemostasis will 
depends up on the site of external carotid artery. If the hemorrhage was in the proximal part then surgery would be preferred over the embolization therapy $[12,13]$. Therefore the relation of site of origin of facial artery from external carotid artery is important in such cases.

In present case, facial artery was superficial along the posterior border of the mandible and also crossing posterior belly of diagastric and stylohyoid superficially. In such situation facial artery is liable to be injured during incisions along the posterior border and angle of mandible. Artery may also get severed during mandibulectomy and during radical neck dissection in present situation.

\section{Conclusion}

Sound knowledge of vascular anatomy is essential during surgical procedures like mandibular ramus osteotomy, hemi-mandibulectomy, angle reduction, parotidectomy. Such situation may complicate the surgery. Therefore maxillofacial surgeon, plastic surgeon and head \& neck surgeon should be careful in case of such variations.

\section{References}

1. Hollinshead WH (1954) The head and neck. In: Anatomy for surgeons, vol 1. A Hoeber \& Harper book, United States of America, p 306-339

2. Tubbs RS, Salter EG, Oakes WJ (2005) Unilateral agenesis of the facial artery with compensation by a giant transverse facial artery. Folia Morphol 64(3):226-228
3. Kubota K (1950) Eine seltene anomalie von Verzweigungen der A. carotis communis. Acta Anat Nipón 25:22-24

4. Matsumoto M, Okuda H, Ishidoh E, Mitsui H (1986) An anomalous case of common carotid artery living off several branches of higher division of the internal carotid artery. Okajimas Folia Anat Jpn 63:37-44

5. Zumre O, Salbacak A, Cicekcibasi AE et al (2005) Investigation of the bifurcation level of common carotid artery and variations of branches of external carotid artery in human fetuses. Ann Anat 187:361-369

6. Basekim CC, Silit E, Mutlu H, Pekkafali MZ, Ozturk E, Kizilkaya E (2004) Type I proatlantal artery with bilateral absence of the external carotid arteries. Am J Neuroradiol 25:1619-1621

7. Nayak S (2006) Abnormal intra-parotid origin of the facial artery. Saudi Med J 27:1602

8. Rao KGM, Rodrigues V, Shajan K, Krishnasamy N, Radhakrishnan AM (2009) Unilateral high origin of facial artery associated with a variant origin of the glandular branch to the submandibular gland. Int J Anat Var 2:136-137

9. Hagan WE, Walker LB (2009) The nasolabial musculocutaneous flap: clinical and anatomical correlations. Laryngoscope 98(3):341-346

10. Furukawa M, Mathes DW, Anzai Y (2013) Evaluation of the facial artery on computed tomographic angiography using 64-slice multidetector computed tomography: implications for facial reconstruction in plastic surgery. Plast Reconstr Surg 131(3):526-535

11. Li SH, Hsu SW, Wang SL, Chen HC, Huang CH (2007) Pseudoaneurysm of the external carotid artery branch following radiotherapy for nasopharyngeal carcinoma. Jpn J Clin Oncol 37(4):310-313

12. Morrissey DD, Andersen PE, Nesbit GM, Barnwell SL, Everts EC, Cohen JI (1997) Endovascular management of hemorrhage in patients with head and neck cancer. Arch Otolaryngol Head Neck Surg 123:15-19

13. Yuen JC, Gray DJ (2000) Endovascular treatment of a pseudoaneurysm of a recipient external carotid artery following radiation and free tissue transfer. Ann Plast Surg 44:656-659 